This is a postprint of an article published in

Goldmann, O., Lehne, S., Medina, E.

Age-related susceptibility to Streptococcus pyogenes infection in mice:

Underlying immune

dysfunction and strategy to enhance immunity

(2010) Journal of Pathology, 220 (5), pp. 521-529. 


\title{
Age-Related Susceptibility to Streptococcus pyogenes Infection in Mice: Underlying Immune Dysfunction and Strategy to Enhance Immunity*
}

\author{
Running head: Age-related susceptibility to S. pyogenes \\ Oliver Goldmann, Sabine Lehne, and Eva Medina ${ }^{1}$
}

Infection Immunology Research Group, Department of Microbial Pathogenesis, Helmholtz

Centre for Infection Research, Inhoffenstraße 7, D-38124 Braunschweig, Germany.

${ }^{1}$ Corresponding author: Infection Immunology Research Group, Helmholtz Centre for Infection Research, Inhoffenstraße 7, 38124 Braunschweig, Germany. Phone: +49 5316181 4500; fax: +49 5316181 4499; E-mail: eva.medina@helmholtz-hzi.de

This work was supported by internal funds of the Helmholtz Centre for Infection Research.

Word counts Text: 3222

*No conflicts of interest were declared 


\begin{abstract}
Epidemiological studies have shown that the elderly are at higher risk of severe Streptococcus pyogenes infections. In this study, we used a mouse model that displays the age-related loss of resistance to $S$. pyogenes infection seen in humans to investigate the impaired immune mechanism underlying the age-associated susceptibility to this pathogen. Young (2-3 monthsold) and aged ( $>20$ month-old) BALB/c mice were subcutaneously or intravenously inoculated with $S$. pyogenes and their capacity to control infection was compared. Aged mice showed faster progression of disease, earlier morbidity and increased mortality when compared with young animals. Since macrophages are critical for host defence against $S$. pyogenes, we investigated whether susceptibility of aged mice may be due to an ageassociated decline in the functionality of these cells. Our results showed that macrophages from aged mice were as capable as those from young animals to uptake and kill S. pyogenes, but the number of resident tissue macrophages was significantly reduced in the aged host. Treatment of aged mice with macrophage colony stimulating factors (M-CSF) significantly increased the number of resident macrophages and improved their response to infection. Our results indicate that treatment with M-CSF can restore, at least in part, the mechanisms affected by immunosenescence and enhance natural resistance of aged mice to infection with S. pyogenes.
\end{abstract}

Key word: Aging, Streptococcus pyogenes, macrophages, immunosenescence. 


\section{INTRODUCTION}

With the continuous global increase in life expectancy, it is expected that by the middle of the 21 st century more than $20 \%$ of the population will be over the age of 65 [1]. One major health issue arising with age is the increasing prevalence and severity of some infectious diseases, which partly reflects the age-related decline in the functionality of the immune system $[2,3]$. The changes occurring within the immune system of the ageing individual are extensive, with major changes in T-cell responses, including increasing frequency of memory phenotype cells, clonal exhaustion, thymic involution and disrupted costimulation [4-8]. Defects in humoral immunity, especially in the ability to generate particular antibody isotypes have been reported [9]. Several studies have also shown that age-related defects in the immune system are not restricted to adaptive immunity but can also be extended to the innate immune response $[10,11]$. Thus, neutrophils, macrophages and NK cells, important first line of defence against bacterial infections, are impaired with advancing age [12-14].

Age-associated decreases in immune function seem to contribute greatly to the increased susceptibility of elderly individuals to specific bacterial infections. In this regard, epidemiological investigations have shown that $S$. pyogenes (the group A streptococci) is an important cause of severe and life-threatening infections among the elderly population [1518]. Although $S$. pyogenes is the most common cause of pharyngitis and soft tissue infections, it can also produce severe invasive diseases including bacteremia, necrotizing fasciitis and septic shock [19]. Even though invasive infections comprise only a small proportion of the total burden of streptococcal diseases, they are associated with high morbidity and mortality with the highest incidence and fatality rate occurring in the population over 65 years of age [20]. Therefore, there is an increasing need to identify strategies that can protect the elderly against this insidious pathogen. To develop theses preventative or therapeutic strategies, it is imperative to identify the deficiencies that lead to the increased susceptibility of the elderly to S. pyogenes.

Studies addressing the age-related changes in the immune system that affect the response to infection are in general, difficult to perform in ageing individuals because of the high incidence of co-morbidity and the frequent use of medication. In this regard, the mouse model has proved to be a very useful tool to understand the basis for increased susceptibility to infection that accompanies advance age. Here, we have used a well-defined murine model of S. pyogenes infection to fulfil the following objectives: (i) to compare the efficiency of the immune defence mechanisms of aged ( $<20$ months-old) and young (2-3 months-old) mice to control S. pyogenes infection; (ii) to define the mechanisms by which aged mice may be more susceptible than young animals to infection with this pathogen; (iii) to assess new preventative or therapeutic measures to improve the capacity of the elderly immune system to fight and defeat $S$. pyogenes. 


\section{MATERIALS AND METHODS}

Bacteria. S. pyogenes A20 strain is a human isolate obtained from the German Culture Collection (DSM 2071). Stocks were maintained at $-70^{\circ} \mathrm{C}$ and were routinely cultured at $37^{\circ} \mathrm{C}$ in Todd-Hewitt broth (Oxoid), supplemented with 1\% yeast extracts. Bacteria were collected in mid-log-phase, washed twice with sterile PBS, diluted to the required inoculum and the number of viable bacteria determined by counting CFU after diluting and plating on blood agar plates (GIBCO) containing 5\% sheep blood.

Mice. Female BALB/c mice were purchased from Harlan-Winkelmann (Borchen, Germany) and used for experiments when they were $<20$ months-old (aged) or 2-3 months-old (young). Mice were housed in micro-isolator cages and kept under pathogen-free conditions. All animal experiments were approved by the local ethical board (Niedersächsisches Landesamt für Verbraucherschutz und Lebensmittelsicherheit, Oldenburg, Germany).

Experimental infection models. For the subcutaneous infection model, young and aged mice were anaesthetized with Isoba ${ }^{\circledR}$ (Essex, Munich, Germany) and infected subcutaneously with the indicated amount of $S$. pyogenes in $100 \mu 1$ of PBS at the right front flank. For the intravenous infection model, S. pyogenes was inoculated into the animals via the lateral tail vein. Mice were observed daily and mortality was recorded. In addition, some mice were sacrificed by $\mathrm{CO}_{2}$ inhalation at specific time intervals to measure bacterial burdens in systemic organs and serum parameters. Organs were homogenized in PBS, serially diluted, and plated onto blood agar. Colonies were enumerated $24 \mathrm{~h}$ thereafter and results expressed as $\log _{10}$ CFU per organ.

In some experiments, mice were treated intraperitoneally with $0.5 \mathrm{mg}$ of carrageenan (type IV $\lambda$; Sigma) 2 days prior to bacterial challenge to achieve partial depletion of resident macrophages.

Determination of $\mathbf{L} \boldsymbol{D}_{50}$. Groups $(\mathrm{n}=10)$ of young and aged mice were subcutaneously inoculated with either $10^{7}, 10^{6}$ or $10^{5} \mathrm{CFU}$ of $S$. pyogenes and mortality was scored over a period of 12 days. The $50 \%$ lethal dose $\left(\mathrm{LD}_{50}\right)$ of $S$. pyogenes for young and aged mice was calculated by the method of Reed and Muench [21].

Cytokines ELISA. The determination of TNF- $\alpha$, IFN- $\gamma$, IL-12 and IL-6 was performed by specific ELISA as previously described [22].

FACS analysis. Cell suspensions were incubated for 5 min with anti-CD32/CD16 antibodies to block the Fc receptors and then stained with phycoerythrin (PE)-conjugated anti-F4/80 (macrophages), anti-CD11c (dendritic cells), anti-Gr-1 (neutrophils), anti-B220 (B cells), antiCD4 (CD4+ T cells) or anti-CD8 (CD8+ T cells) antibodies (PharMingen) and incubated for 30 min at $4^{\circ} \mathrm{C}$. Labelled cells were analysed by flow cytometry in a FACScan (Becton Dickinson).

Isolation and infection of bone marrow-derived macrophages. Isolation and differentiation of murine bone marrow macrophages was performed as previously described [23]. Macrophages were infected with 10 bacteria per macrophage (10:1 MOI) and incubated for 2 $\mathrm{h}$ at $37^{\circ} \mathrm{C}, 5 \% \mathrm{CO}_{2}$. Macrophages were then washed with sterile PBS, resuspended in complete medium containing $100 \mu \mathrm{g} / \mathrm{ml}$ of gentamicin to kill non-ingested bacteria, and further incubated at $37^{\circ} \mathrm{C}, 5 \% \mathrm{CO}_{2}$. At the indicated time points, macrophages were disrupted with distilled $\mathrm{H}_{2} \mathrm{O}$ to release intracellular bacteria, the resulting suspension was serially diluted and bacterial numbers were determined after plating onto blood agar. 
Therapeutic treatment with M-CSF. M-CSF was obtained from Sigma and administered to aged mice by intraperitoneal injection, using a daily dose of $5 \mu \mathrm{g}$ per mouse starting $24 \mathrm{~h}$ prior to bacterial inoculation.

Statistical analysis. Survival curves were analysed by the log-rank test. Data were analysed in Excel 2000 (Microsoft Office) or GraphPad Prism 4.0 (GraphPad software). All data are presented as mean $\pm \mathrm{SD}$. Comparison between groups was performed using the nonparametric $t$-test. $P$ values $\leq 0.05$ were considered as significant. 


\section{RESULTS}

Aged mice exhibit greater susceptibility than young mice to systemic infection with $S$. pyogenes. We have previously shown that young BALB/c mice are very resistant to $S$. pyogenes infection initiated either subcutaneously or intravenously [22, 24]. In this study, we investigated the potential influence of age in the response to $S$. pyogenes infection in BALB/c mice. For this purpose, the mortality rates of aged ( $<20$ months-old) versus young (2-3 months-old) mice after subcutaneous inoculation with $10^{5} \mathrm{CFU}$ of $S$. pyogenes were compared. The results in Fig. 1A show that while all aged mice died by day 12 of infection, none of the young mice died within this period of 12 days. The cumulative survival among young and aged mice was then determined following subcutaneous inoculation with four different doses of $S$. pyogenes $\left(10^{7}, 10^{6}, 10^{5}\right.$ or $\left.10^{4} \mathrm{CFU}\right)$ (Table 1$)$. The $\mathrm{LD}_{50}$ of subcutaneous $S$. pyogenes was calculated as $2 \times 10^{6} \mathrm{CFU}$ for young and $10^{4} \mathrm{CFU}$ for aged animals.

To determine whether the high mortality observed in the aged mice was associated with a lower capacity to contain infection, bacterial growth was assessed in the systemic organs of young and aged mice at increasing times after bacterial inoculation. In contrast to the effective control of infection exhibited by young mice, aged animals were unable to contain bacterial growth and developed severe septicaemia shortly after bacterial inoculation. Progressive bacterial growth was evident in the liver (Fig. 2B) and spleen (Fig. 2C) of aged mice but not in the organs of young animals. These results suggest that the greater susceptibility exhibited by aged mice to $S$. pyogenes infection is associated with an impaired capacity to control bacterial growth.

The age-associated differences in susceptibility to $S$. pyogenes was independent of the route of inoculation since similar differences between aged and young mice were observed when S. pyogenes was given intravenously (Supporting information, Supplementary Figure $1)$.

\section{Aged mice exhibited greater levels of systemic inflammation during $S$. pyogenes infection than young animals.}

As elevated levels of inflammatory cytokines have been associated with morbidity in patients with severe invasive $S$. pyogenes infections [25-27], we compared the serum levels of inflammatory cytokines in $S$. pyogenes-infected young and aged mice at $48 \mathrm{~h}$ after bacterial inoculation, the time of infection at which dissemination of $S$. pyogenes to the systemic organs was observed. As seen in Fig. 2, significantly greater levels of TNF- $\alpha$ (Fig. 2A), IL-6 (Fig. 2B), IFN- $\gamma$ (Fig. 2C) and IL-12 (Fig. 2D) were detected in the serum of infected aged mice than in the serum of young animals. The increased levels of inflammatory cytokines in the serum of aged mice most probably reflect the sustained systemic infection occurring in these animals.

\section{Macrophages from aged mice are not impaired in their capacity to phagocyte and kill $S$. pyogenes.}

Having demonstrated the impaired capacity of aged mice to control the growth of streptococci during infection, we sought to investigate the immune function responsible for this deficit. Because resident macrophages play a critical role in the early control of $S$. pyogenes [28, 29] and recent studies have shown age-related defects in the functional activity of these cells [13], we hypothesised that an age-associated decline in macrophage function may account for the age-related susceptibility to $S$. pyogenes. To evaluate this, we first determined the capacity of macrophages to phagocyte and kill streptococci, in both young and aged mice. For this purpose, macrophages derived from bone marrow of young and aged mice were infected in vitro with $S$. pyogenes at a MOI of 1:10 for $2 \mathrm{~h}$ to allow bacterial phagocytosis. Gentamicin was then added to kill extracellular non-ingested bacteria and the amount of internalised $S$. 
pyogenes was determined after releasing bacteria from infected macrophages and plated on blood agar. As illustrated in Fig. 3A, no differences were observed between macrophages from young and aged mice in their ability to uptake $S$. pyogenes. The kinetic data presented in Fig. 3B shows that macrophages from aged mice were as capable as those from young animals to eradicate the internalised microorganisms. Nevertheless, bacterial killing seems to be faster in macrophages from young mice as shown by the significantly lower amount of bacteria at $3 \mathrm{~h}$ postinfection (Fig. 3B).

\section{Aged mice have significantly lower amounts of resident tissue macrophages than young animals.}

Macrophages originate in the bone marrow and migrate to body tissue through blood where they differentiate into the specific tissue macrophage types and multiply under the influence of cytokines and growth factors present in the tissue environment. It has been suggested that ageing impacts tissue environment and consequently the functional homeostasis of macrophages [30]. In addition, several studies have reported a reduction in the number of alveolar macrophages with increasing age [30-32]. As macrophages from aged mice were not affected in their anti-microbial activity against $S$. pyogenes, we speculated that an ageassociated loss of resident tissue macrophages may be responsible for the increased susceptibility of aged mice. To test this hypothesis, we first sought to determine whether young and aged mice differed in the number of resident macrophages present in the systemic compartment. Interestingly, a significantly lower amount of macrophages were recovered from the peritoneal cavity (Fig. 4A) and spleen (Fig. 4B) of the aged mice as compared to the young animals. These results indicate that an altered number of macrophages may be responsible for the impaired bacterial clearance observed in aged mice. We also examined the frequency of other cell populations including dendritic cells, neutrophils, B and T cells in the peritoneal cavity of young and aged mice. However, the only cell population that significantly differed between young and aged mice was the B cells subset, in this case significantly increased in the peritoneal cavity of aged mice than in that of the young mice (Supporting information, Supplementary Figure 2).

To assess the consequences of a reduced amount of resident macrophages in the capacity of mice to control S. pyogenes infection, young mice were partially depleted of resident macrophages and then infected intravenously with $S$. pyogenes. As shown in Fig. 5A, treatment of young mice with $0.5 \mathrm{mg}$ of carrageenan induced partial depletion of resident macrophages. The partially-depleted mice demonstrated significantly shorter survival times (Fig. 5B) and $\sim 1.5 \log$ increase in bacteria in the liver (Fig. 5C) than non-depleted animals at $48 \mathrm{~h}$ after bacterial inoculation. These results provide definitive evidence that a reduction in the resident macrophage compartment can have a significant impact in the capacity of mice to control S. pyogenes infection.

\section{Restoration of resident macrophages in aged mice after treatment with M-CSF.}

The age-associated loss of resident macrophages may be a consequence of an age-related dysfunctional haematopoiesis and shrinkage in the production of haematopoietic growth factors, as previously reported [33]. Based on the central role of colony-stimulating factor 1 (M-CSF or CSF-1) for regulating the production, maintenance and function of macrophages $[33,34]$, in addition to the observation that intravenous administration of recombinant human M-CSF into mice causes a dose-dependent increase in the numbers of circulating monocytes and tissue macrophages [35], we next determined whether in vivo treatment of aged mice with $\mathrm{M}-\mathrm{CSF}$ can increase the number of effector resident macrophages in aged mice. For this purpose, aged mice were treated with M-CSF and the percentage of macrophages in the peritoneal cavity was determined $24 \mathrm{~h}$ thereafter. The results depicted in Fig. 6A show a 
significant increase in the frequency of resident peritoneal macrophages in aged mice after treatment with M-CSF when compared with PBS-treated animals.

To determine whether the increased amount of resident macrophages induced by M-CSF treatment translated into increased resistance to $S$. pyogenes infection, aged mice were treated with M-CSF and challenged with S. pyogenes. M-CSF treatment afforded $\sim 1$ log reduction in S. pyogenes loads in the liver compared with PBS-treated control animals (Fig. 6B). The levels of TNF- $\alpha$ were also significantly lower in M-CSF-treated aged mice than in aged mice receiving PBS (Fig. 6C). Therefore, treatment with M-CSF significantly increased the frequency of resident tissue macrophages and improved the capacity of aged mice to control S. pyogenes infection. 


\section{DISCUSSION}

Age is clearly a risk factor for severe $S$. pyogenes infection in humans [15-18]. The goal of the present study was to use a murine model of $S$. pyogenes infection that exhibits the agerelated loss of resistance seen in humans to define specific deficiencies in the immune function that lead to the age-related increase in susceptibility to infection. This murine model of streptococcal infection was also used to evaluate new approaches to enhance the resistance of the aged host during encounters with this pathogen.

We have shown here that mice became more susceptible to $S$. pyogenes infection with increasing age. The increased susceptibility of aged mice was manifested by a complete failure to control bacterial growth after systemic challenge. Our objective was then to identify which immune mechanisms involved in bacterial clearance are impaired in the aged host. Given the importance of resident macrophages in combating $S$. pyogenes infection, we examined the potential impact of age in the anti-microbial activity of macrophages against this pathogen. In the assessment of macrophage function, we observed no differences in the phagocytosis and eradication of $S$. pyogenes when comparing macrophages from young and aged animals. This suggests that the increase vulnerability of the aged mice to severe streptococcal infection may reflect age-related physiological changes that are not related to macrophage dysfunction per se and that other age-associated factors may indirectly have an impact in macrophage function. In this regard, it has been shown that stromal environment of different organs such as bone marrow or spleen change with age, resulting in reduced haematopoiesis and peripheral homeostasis [30]. Therefore, we then considered the possibility that the deficient control of bacterial growth observed in aged mice may be caused by a disruption in the functional homeostasis of macrophages rather than by an age-associated intrinsic defect in the lineage. We proved this assumption by demonstrating that aged mice had a significantly lower number of resident tissue macrophages than young animals. The impact of a reduced number of resident macrophages in the capacity of mice to control $S$. pyogenes infection was further demonstrated by the exacerbation of infection observed in young mice after partial depletion of resident macrophages. Reduction of resident macrophages in aged mice has been observed in previous studies with different infection models. Antonini et al. [32] reported a decrease in total number of alveolar macrophages retrieved by bronchoalveolar lavage in aged rats as compared to young rats. In the same study, the authors found no differences between aged and young animals in the functionality of alveolar macrophages but they observed an increase in mortality and pulmonary inflammation in the aged rats after intratracheal challenge with bacterial pathogens [32]. Decline of resident immune cells with age is not limited to tissue macrophages since studies of aged mice have shown that the density of Langerhans cells in the epidermis and dendritic cells in Peyer's patches and spleens also declines in aged mice [37-40]. A reduction in plasmacytoid dendritic cells in peripheral blood of elderly individuals has been also reported [41].

If age-related changes in macrophage function are caused by the impact of ageing in tissue environments, these functional changes may be reversible rather than intrinsic.

Therefore, boosting the regulatory factors in the aged environment may restore, at least in part, the effector functions of macrophages. The proliferation, differentiation, survival and mature function of mononuclear phagocytes are regulated by M-CSF [34]. Intravenous administration of recombinant human M-CSF into mice has been shown to cause a dosedependent increase in the numbers of circulating monocytes and tissue macrophages [35]. For these reasons, we evaluated whether treatment with M-CSF could induce repopulation of resident tissue macrophages in aged mice and increase immunity in this animals during infection. Our results show that indeed, treating aged mice with M-CSF induced a significant increase in the number of resident tissue macrophages that translated in enhanced natural resistance to $S$. pyogenes. The augmentation of tissue macrophages in aged mice after treatment with M-CSF can be explained by the stimulation of in situ proliferation of existing 
resident macrophages and/or by enhancing monocytes migration from blood into tissue. This beneficial effect of M-CSF on enhancing resistance of aged mice to $S$. pyogenes infection coupled with the favourable safety profile of studies employing human M-CSF in clinical trials [42] could be of interest for the development of new approaches to temporarily increase immunity of aged individuals against $S$. pyogenes and probably against other pathogens.

In summary, the results presented here demonstrate that an age-related decline in the amount of resident tissue macrophages may contribute to the vulnerability of aged mice to streptococcal infection. In any event, it should be clear that due to the high degree of complexity of the immune system, coupled with its interactions with the nervous and the endocrine systems, a holistic approach is needed for a more comprehensive understanding of the basis for increased susceptibility to infection in the elderly population. 
ACKNOWLEDGMENTS

The authors would like to thank Claudia Höltje for excellent technical assistance. 


\section{REFERENCES}

1. Lutz W, Sanderson W, Scherbov S. Doubling of world population unlikely. Nature 1997; $387: 803-805$.

2. Gavazzi G, Krause KH. Ageing and infection. Lancet Infect Dis 2002; 2 :659-666.

3. Yoshikawa TT. Epidemiology and unique aspects of ageing and infectious diseases. Clin Infect Dis 2000; 30 :931-933.

4. Ernst DN, Weigle WO, Noonan DJ, McQuitty DN, Hobbs MV. The age-associated increase in IFN-gamma synthesis by mouse CD8+ T cells correlates with shifts in the frequencies of cell subsets defined by membrane CD44, CD45RB, 3G11, and MEL-14 expression. J Immunol 1993; 151 :575-587.

5. Utsuyama M, Hirokawa K, Kurashima C, Fukayama M, Inamatsu T, Suzuki K, et al. Differential age-change in the numbers of CD4+CD45RA+ and CD4+CD29+ T cell subsets in human peripheral blood. Mech Ageing Dev 1992; 63 :57-68.

6. Weng NP, Palmer LD, Levine BL, Lane HC, June CH, Hodes RJ. Tales of tails: regulation of telomere length and telomerase activity during lymphocyte development, differentiation, activation, and ageing. Immunol Rev 1997; 160 :43-54.

7. Taub DD, Longo DL. Insights into thymic ageing and regeneration. Immunol Rev 2005; $205: 72-93$.

8. Engwerda CR, Handwerger BS, Fox BS. Aged T cells are hyporesponsive to costimulation mediated by CD28. J Immunol 1994; $152: 3740-3747$.

9. Cancro MP, Hao Y, Scholz JL, Riley RL, Frasca D, Dunn-Walters DK, et al. B cells and aging: molecules and mechanisms. Trends Immunol 2009; 30:313-318.

10. Panda A, Arjona A, Sapey E, Bai F, Fikrig E, Montgomery RR, et al. Human innate immunosenescence: causes and consequences for immunity in old age. Trends Immunol 2009; $30: 325-333$.

11. Gomez CR, Nomellini V, Faunce DE, Kovacs EJ. Innate immunity and ageing. Exp Gerontol 2008; 43 :718-728.

12. Fortin CF, McDonald PP, Lesur O, Fülöp T Jr. Ageing and neutrophils: there is still much to do. Rejuvenation Res 2008; $11: 873-882$.

13. Lloberas J, Celada A. Effect of ageing on macrophage function. Exp Gerontol 2002; 37 :1325-1331.

14. Peralbo E, Alonso C, Solana R. Invariant NKT and NKT-like lymphocytes: two different T cell subsets that are differentially affected by ageing. Exp Gerontol 2007; 42 :703-708.

15. O'Loughlin RE, Roberson A, Cieslak PR, Lynfield R, Gershman K, Craig A, et al. Active Bacterial Core Surveillance Team: The epidemiology of invasive group A streptococcal infection and potential vaccine implications: United States, 2000-2004. Clin Infect Dis 2007; $45: 853-862$.

16. Jordan HT, Richards CL, Jr., Burton DC, Thigpen MC, Van Beneden CA. Group A streptococcal disease in long-term care facilities: descriptive epidemiology and potential control measures. Clin Infect Dis 2007; 45: 742-752

17. Rainbow J, Jewell B, Danila RN, Boxrud D, Beall B, Van Beneden C, et al. Invasive group A streptococcal disease in nursing homes, Minnesota, 1995-2006. Emerg Infect Dis 2008; $14: 772-777$.

18. Lamagni TL, Darenberg J, Luca-Harari B, Siljander T, Efstratiou A, Henriques-Normark B, et al. Epidemiology of severe Streptococcus pyogenes disease in Europe. J Clin Microbiol 2008; 46 :2359-2367.

19. Jaggi P, Shulman ST. Group A streptococcal infections. Pediatr Rev 2006; 27 :99-105.

20. Prevention CfDCa: Active Bacterial Core Surveillance (ABCs) reports, Emerging Infections Program Network 2007: group A Streptococcus 1998-2003. Available from http://wwwcdcgov/ncidod/dbmd/abcs/survreportshtm 
21. Reed LJ, Muench H. A simple method for estimating fifty percent end points. Am J Hyg 1938; 27 :493-497.

22. Goldmann O, Chhatwal GS, Medina E. Immune mechanisms underlying host susceptibility to infection with group A streptococci. J Infect Dis 2003; $187: 854-861$. 23. Goldmann O, Sastalla I, Wos-Oxley M, Rohde M, Medina E. Streptococcus pyogenes

induces oncosis in macrophages through the activation of an inflammatory programmed cell death pathway. Cell Microbiol 2009; $11: 138-155$.

24. Medina E, Goldmann O, Rohde M, Lengeling A, Chhatwal GS. Genetic control of susceptibility to group A streptococcal infection in mice. J Infect Dis 2001; 184 :846-852. 25. Cavaillon JM, Muller-Alouf H, Alouf JE. Cytokines in streptococcal infections. An opening lecture. Adv Exp Med Biol 1997; 418 :869-879.

26. Norrby-Teglund A, Chatellier S, Low DE, McGeer A, Green K, Kotb M. Host variation in cytokine responses to superantigens determine the severity of invasive group A streptococcal infection. Eur J Immunol 2000; $30: 3247-3255$.

27. Norrby-Teglund A, Pauksens K, Norgren M, Holm SE. Correlation between serum TNF alpha and IL6 levels and severity of group A streptococcal infections. Scand J Infect Dis $1995 ; 27: 125-130$.

28. Goldmann O, Rohde M, Chhatwal GS, Medina E. Role of macrophages in host resistance to group A streptococci. Infect Immun 2004; 72 :2956-2963.

29. Goldmann O, Lengeling A, Bose J, Bloecker H, Geffers R, Chhatwal GS, et al. The role of the MHC on resistance to group A streptococci in mice. J Immunol 2005; 175 :3862-3872.

30. Stout RD, Suttles J. Immunosenescence and macrophage functional plasticity:

dysregulation of macrophage function by age-associated microenvironmental changes.

Immunol Rev 2005; $205: 60-71$.

31. Clarke RW, Antonini JM, Hemenway DR, Frank R, Kleeberger SR, Jakab GJ. Inhaled particle-bound sulfate: effects on pulmonary inflammatory responses and alveolar macrophage function. Inhal Toxicol 2000; 12 :169-186.

32. Antonini JM, Roberts JR, Clarke RW, Yang HM, Barger MW, Ma JY, et al. Effect of age on respiratory defense mechanisms: pulmonary bacterial clearance in Fischer 344 rats after intratracheal instillation of Listeria monocytogenes. Chest 2001; 120 :240-249.

33. Buchanan JP, Peters CA, Rasmussen CJ, Rothstein G. Impaired expression of hematopoietic growth factors: a candidate mechanism for the hematopoietic defect of ageing. Exp Gerontol 1996; 31 :135-144.

34. Metcalf D. The molecular biology and functions of the granulocyte-macrophage colonystimulating factors. Blood 1986; 67 :257-267.

35. Ulich TR, del Castillo J, Watson LR, Yin SM, Garnick MB. In vivo hematologic effects of recombinant human macrophage colony-stimulating factor. Blood 1990; 75 :846-850.

36. Hume DA, Pavli P, Donahue RE, Fidler IJ. The effect of human recombinant macrophage colony-stimulating factor (CSF-1) on the murine mononuclear phagocyte system in vivo. $J$ Immunol 1988; $141: 3405-3409$.

37. Sprecher E, Becker Y, Kraal G, Hall E, Harrison D, Schultz LD. Effect of ageing on epidermal dendritic cell populations in C57BL/6J mice. J Invest Dermatol 1990; 94 :247-253. 38. Belsito DV, Epstein SP, Schultz JM, Baer RL, Thorbecke GJ. Enhancement by various cytokines or 2-beta-mercaptoethanol of Ia antigen expression on Langerhans cells in skin from normal aged and young mice. Effect of cyclosporine A. J Immunol 1989; 143 :15301536. 
39. Kato H, Fujihashi K, Kato R, Dohi T, Hagiwara Y, Kataoka K, et al. Lack of oral tolerance in ageing is due to sequential loss of Peyer's patch cell interactions. Int Immunol $2003 ; 15: 145-158$.

40. Linton PJ, Li SP, Zhang Y, Bautista B, Huynh Q, Trinh T. Intrinsic versus environmental influences on T-cell responses in ageing. Immunol Rev 2005; 205 :207-219.

41. Shodell M, Siegal FP. Circulating, interferon-producing plasmacytoid dendritic cells decline during human ageing. Scand J Immunol 2002; 56 :518-521.

42. Nemunaitis J, Meyers JD, Buckner CD, Shannon-Dorcy K, Mori M, Shulman H, et al. Phase I trial of recombinant human macrophage colony-stimulating factor in patients with invasive fungal infections. Blood 1991; 78 :907-913. 


\section{FIGURE LEGENDS}

FIGURE 1. Enhanced susceptibility of aged mice to $S$. pyogenes infection. (A) Survival curves of young (white symbols) and aged (black symbols) mice after subcutaneous infection with $10^{5} \mathrm{CFU}$ of $S$. pyogenes. Comparison of survival curves was performed by use of the Logrank test. S. pyogenes-infected aged mice exhibited significantly shorter survival times than infected young animals $(p<0.001)$. Kinetics of bacterial growth in the spleen (B) and livers (C) of young (white symbols) and aged (black symbols) mice after subcutaneous infection with $10^{5} \mathrm{CFU}$ of $S$. pyogenes. Each point represents the mean $\pm \mathrm{SD}$ of five mice per group. One experiment out of three is shown. ${ }^{* * *}, p<0.001$.

FIGURE 2. Aged mice exhibit greater levels of inflammatory cytokines during $S$. pyogenes infection than young animals. Young and aged mice were infected subcutaneously with $10^{5} \mathrm{CFU}$ of $S$. pyogenes and the serum levels of TNF- $\alpha$ (A), IL-6 (B), IFN- $\gamma(\mathrm{C})$, and IL12 (D) were determined at $48 \mathrm{~h}$ of infection by ELISA. Each bar represents the mean \pm SD of three independent experiments. ${ }^{* *}, p<0.01 ; * * *, p<0.001$.

FIGURE 3. Comparable capacity of macrophages from young and aged mice to phagocyte and kill S. pyogenes. (A) Quantification of S. pyogenes internalised by macrophages derived from either young (white bar) or aged (black bar) mice after $2 \mathrm{~h}$ of infection. Each bar represents the mean \pm SD of three independent experiments. (B) Kinetic of bacterial eradication by macrophages derived from either young (white symbols) or aged (black symbols) mice after in vitro infection with $S$. pyogenes. Each symbol represents the mean $\pm \mathrm{SD}$ of three independent experiments. ${ }^{*}, p<0.05$.

FIGURE 4. Aged mice have significantly lower number of resident tissue macrophages than young animals. (A) Flow cytometry analysis of peritoneal exudates obtained from young (i, iii) and aged (ii, iv) mice. The upper panels are representative dot plot diagrams showing the peritoneal macrophage population (red) in young (i) and aged (ii) mice as determined by the size (FCS-H) and granularity (SSC-H) co-ordinates. The lower panels show the quantification of the amount of macrophages in the peritoneal cavity of young (iii) and aged (iv) mice performed after staining the peritoneal exudates with anti-F4/80 antibodies. One experiment out of three is shown. (B) Quantification of the amount of resident macrophages in the spleen of young (white bar) and aged (black bar) mice. Bars represent the mean $\pm \mathrm{SD}$ of three independent experiments. ${ }^{* * *}, p<0.001$.

Figure 5. Partial depletion of resident macrophages impaired the capacity of young mice to control S. pyogenes infection. Young mice were partially depleted of macrophages by treatment with $0.5 \mathrm{mg}$ of carrageenan 2 days prior to infection and then challenged intravenously with $10^{5} \mathrm{CFU}$ of $S$. pyogenes. Control mice were injected with PBS. (A) Percentage of resident macrophages in the peritoneal cavity of PBS-treated (white bar) or carrageenan-treated (black bar) young mice as determined by flow cytometry. (B) Survival curves of young (white symbols) and aged (black symbols) mice after intravenous infection with $10^{5} \mathrm{CFU}$ of $S$. pyogenes. Comparison of survival curves was performed by use of the Logrank test. S. pyogenes-infected carrageenan-treated young mice exhibited significantly shorter survival times than infected PBS-treated control animals $(p=0.0251)$. (C) Bacterial loads in the livers of PBS- treated (white bar) or carrageenan-treated (black bar) young mice at $48 \mathrm{~h}$ after bacterial inoculation. Each bar represents the mean $\pm \mathrm{SD}$ of three independent experiments. ${ }^{* * *}, p<0.001$. 
FIGURE 6. Treatment with M-CSF leads to increased resident macrophages numbers and enhanced resistance to $S$. pyogenes infection in aged mice. (A) Percentage of macrophages (F4/80+ cells) in the peritoneal cavity of aged mice after treatment with either M-CSF (black bar) or PBS (white bar). (B) Bacterial loads in the liver of aged mice treated with either M-CSF (black bar) or PBS (white bar) at $48 \mathrm{~h}$ of infection with S. pyogenes. (C) Levels of TNF- $\alpha$ in the serum of aged mice treated with either M-CSF (black bar) or PBS (white bar) at $48 \mathrm{~h}$ of infection with $S$. pyogenes. Each bar represents the mean $\pm \mathrm{SD}$ of three independent experiments. ${ }^{*}, p<0.05 ; * * *, p<0.001$. 
Table 1. Survival data analysis of young and aged mice after subcutaneous inoculation with different doses of $S$. pyogenes

\begin{tabular}{|c|c|c|c|c|c|}
\hline \multirow[t]{2}{*}{ Inoculum dose ${ }^{1}$} & \multicolumn{2}{|c|}{$\%$ survival $^{2}$} & \multicolumn{2}{|c|}{ Median survival times } & \multirow[t]{2}{*}{$p$-value ${ }^{3}$} \\
\hline & Young & Aged & Young & Aged & \\
\hline $10^{4}$ & $100 \%$ & $50 \%$ & n.d. & 10 & 0.0118 \\
\hline $10^{5}$ & $100 \%$ & $0 \%$ & n.d. & 6 & $<0.0001$ \\
\hline $10^{6}$ & $60 \%$ & $0 \%$ & n.d. & 6 & 0.016 \\
\hline $10^{7}$ & $30 \%$ & $0 \%$ & 6 & 5 & 0.0543 \\
\hline
\end{tabular}

CFU of $S$. pyogenes

${ }^{2}$ Percentage of mice surviving after 12 days of infection

${ }^{3}$ Comparison of survival curves of young versus aged mice by the Logrank test n.d., undefined 
A

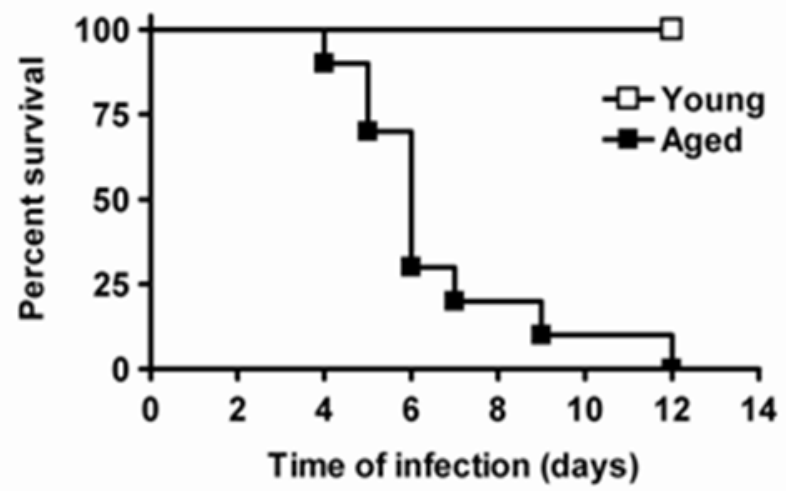

B

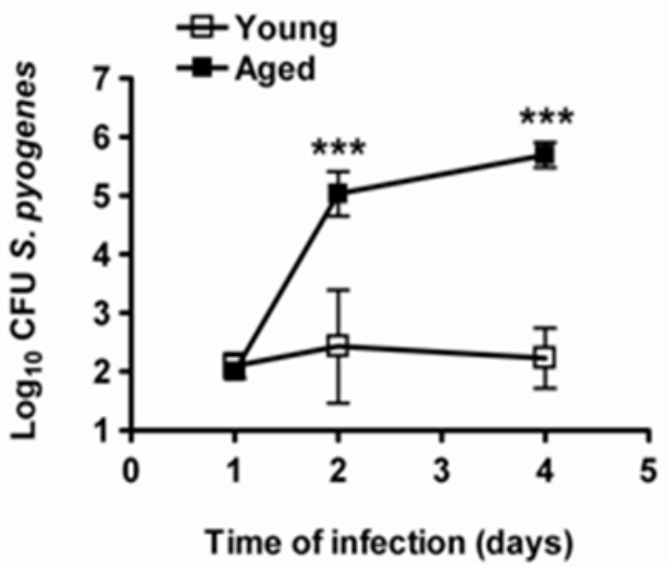

C

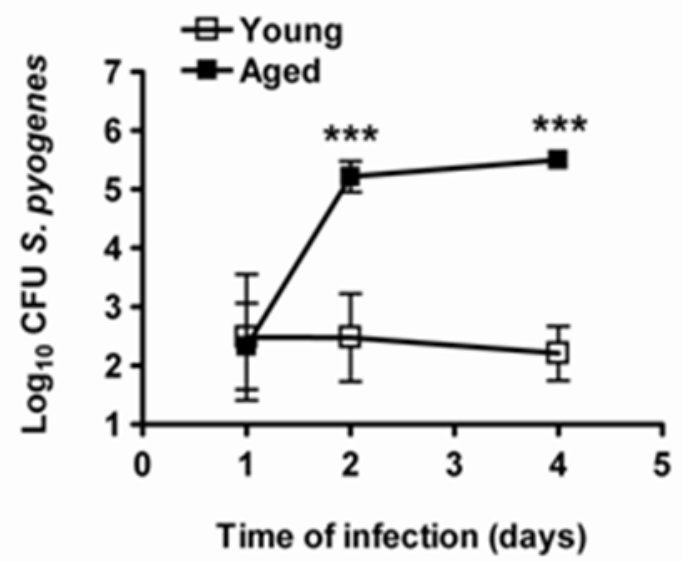

Figure 1 

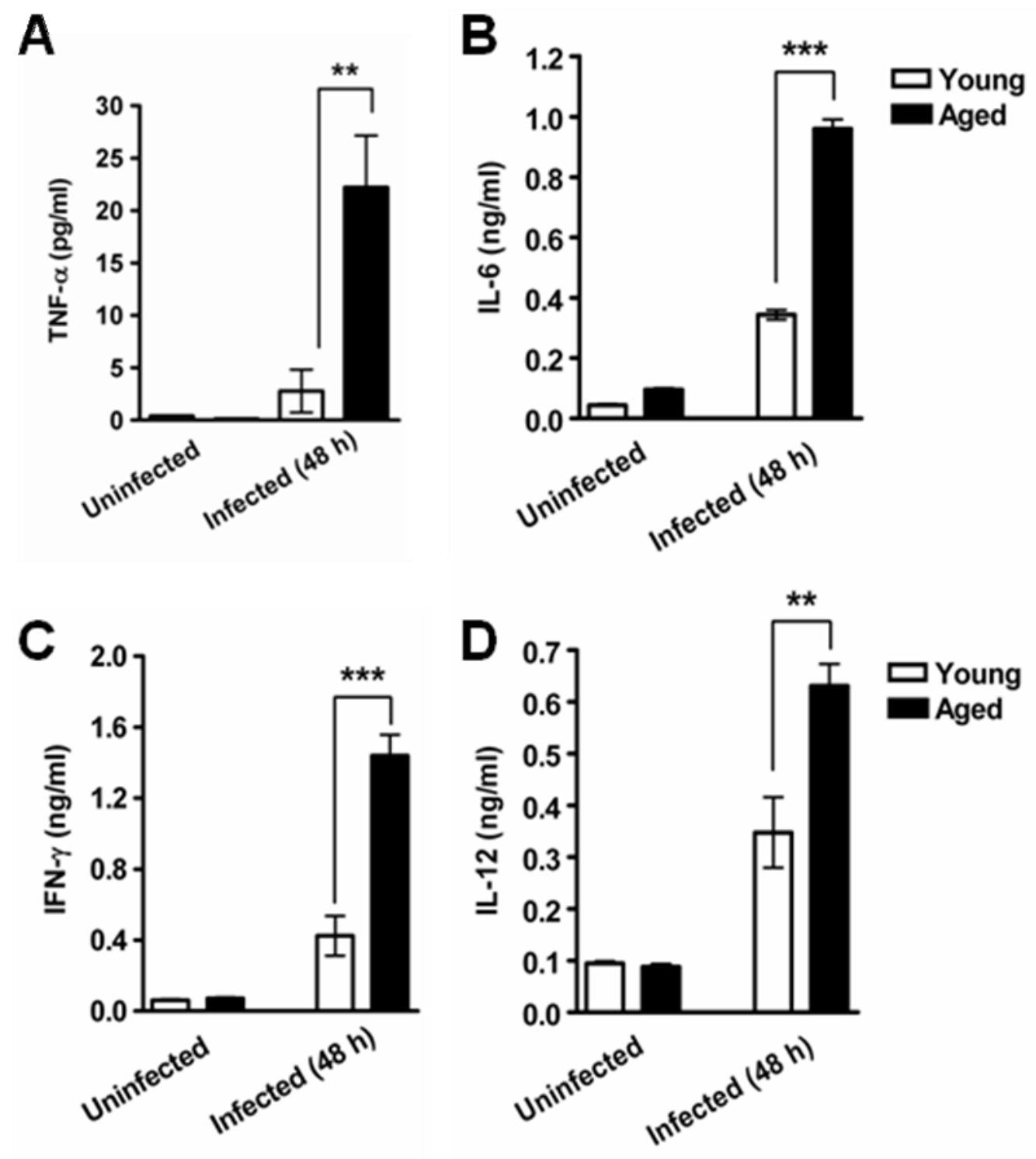

Figure 2 
A

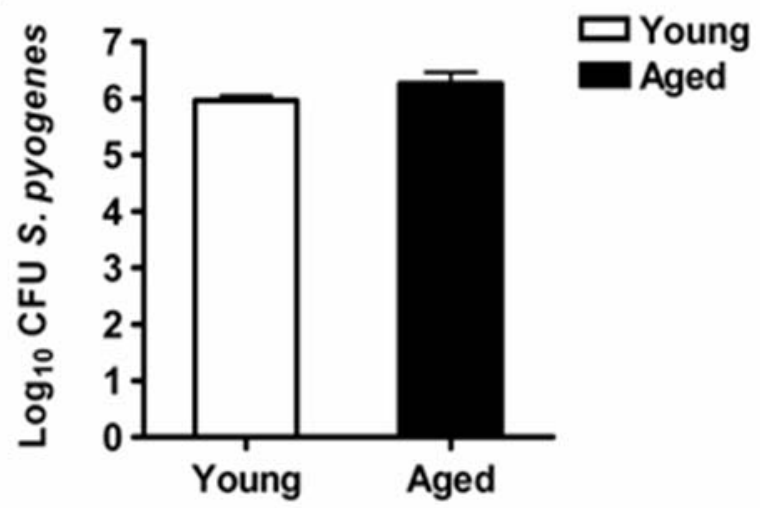

B

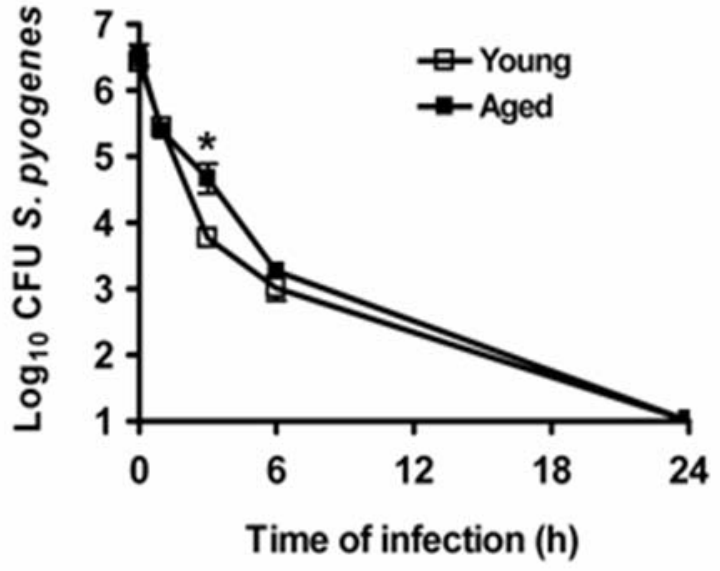

Figure 3 

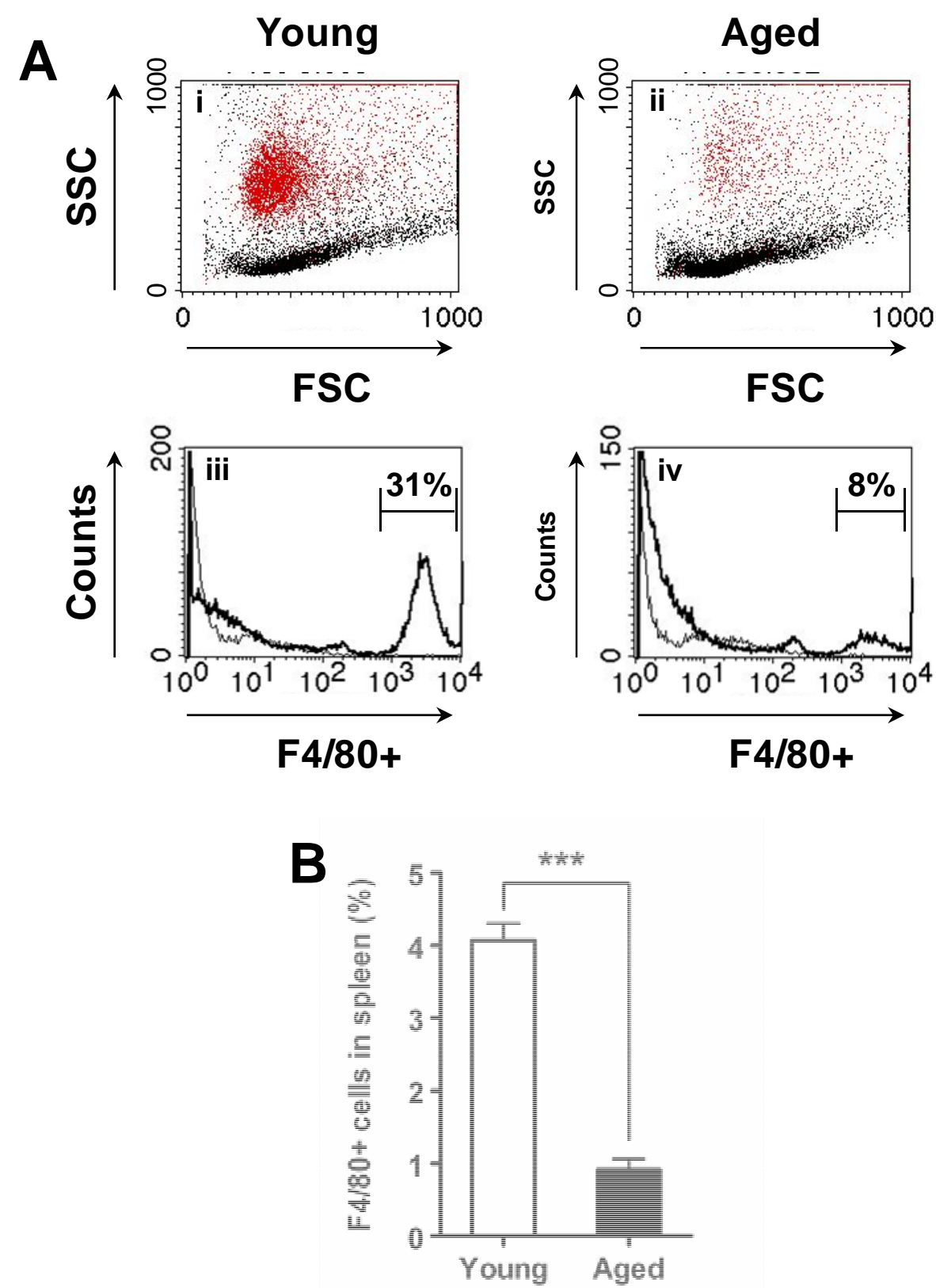

Figure 4 

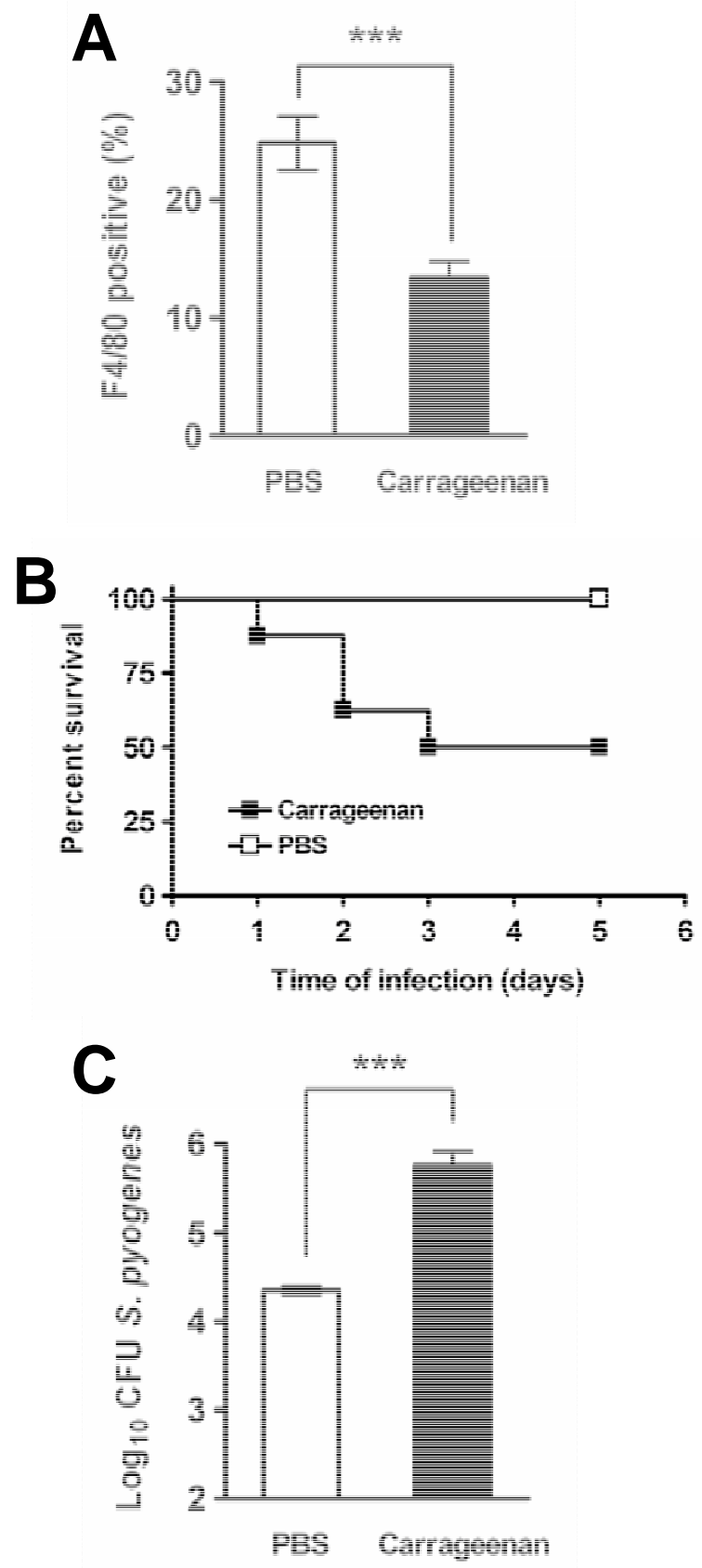

Figure 5 

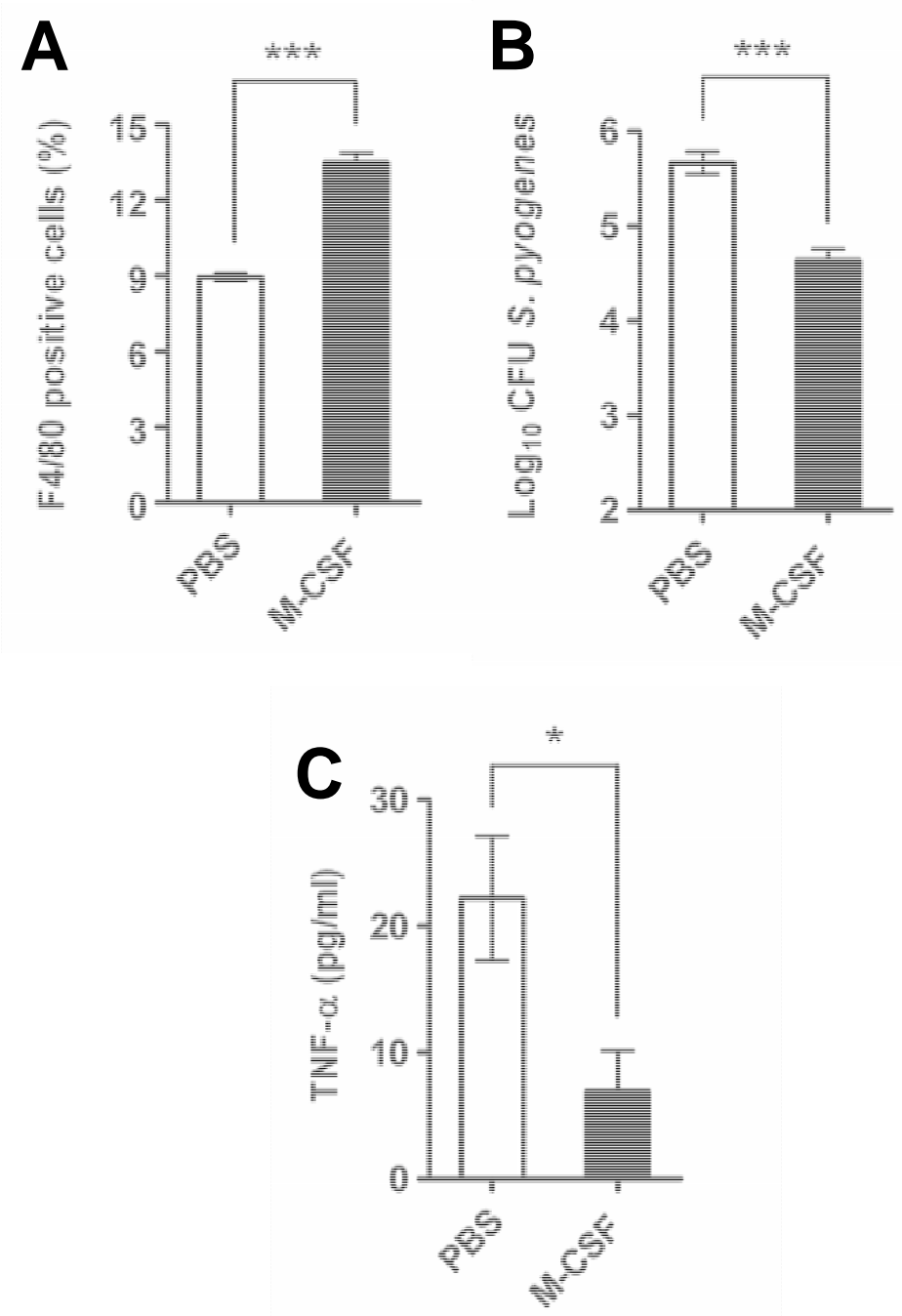

Figure 6 
